\title{
Understanding the Precipitated Calcium Carbonate (PCC) Production Mechanism and Its Characteristics in the Liquid-Gas System Using Milk of Lime (MOL) Suspension
}

\author{
Onimisi A. Jimoha, Tunmise A. Otitoju ${ }^{\mathrm{b}}$, Hashim Hussin ${ }^{\mathrm{a}}$, \\ Kamar Shah Ariffin ${ }^{\mathrm{a}, \mathrm{A}}$ and Norlia Baharun ${ }^{\mathrm{a}}$ \\ ${ }^{a}$ School of Materials and Mineral Resources Engineering, Universiti Sains Malaysia, 14300 Nibong Tebal, \\ Penang, Malaysia. \\ ${ }^{b}$ School of Chemical Engineering, Universiti Sains Malaysia, 14300 Nibong Tebal, Penang, Malaysia.
}

Received 3 April 2016, revised 15 August 2016, accepted 5 September 2016.

\begin{abstract}
This study investigates the effect of operating variables and influence of milk of lime (MOL) conditions in PCC using a modified reactor. The variables includes: $\mathrm{Ca}(\mathrm{OH})_{2}$ feed concentration at $0.5 \mathrm{M}-2.0 \mathrm{M}$ and $\mathrm{CO}_{2}$ flow rates at $224.0 \mathrm{~mL} \mathrm{~min}^{-1}$ and $379.5 \mathrm{~mL} \mathrm{~min}^{-1}$, on the particle morphology and size in the gas-liquid route precipitation. The particle morphology and texture as well as the chemical content were sufficiently authenticated using X-ray diffraction (XRD), Fourier transform infrared spectroscopy (FTIR), scanning electron microscope (SEM) and X-ray fluorescence (XRF). Experimental data show that lower concentration $(<1.0 \mathrm{M})$ favoured the formation of rhombohedra calcite crystals with the particle size below $100 \mathrm{~nm}$. However, increase in concentration and gas flow rate yielded a coarser crystal particles. Two polymorphs were produced at $1 \mathrm{M}$ reactant, i.e. rhombohedra calcite with $\mathrm{CO}_{2}$ flow rate of $224 \mathrm{~mL} \mathrm{~min}^{-1}$ and prismatic calcite at $380 \mathrm{~mL} \mathrm{~min}^{-1}$. Molarities higher than $1 \mathrm{M}$ yielded a coarser prismatic crystals, and also has a tendency to crystallize into scalenohedron species especially with higher reactant concentration.
\end{abstract}

KEYWORDS

Milk of lime, precipitated calcium carbonate, morphology, particle size, carbonation.

\section{Introduction}

Precipitated calcium carbonate (PCC) is a filler used in many applications, like papers, plastics, rubbers, paints, drugs and so on. Its high purity, well-ordered particle size and morphology makes it the white filler of choice. ${ }^{1}$ In paint production, PCC has established itself as a primary extender due to its unique properties such as its low basic colour, high weather resistance, relative abrasiveness, low electrolyte content, non-toxicity and the $\mathrm{pH}$ stabilizing effect. Different kinds of crystal are suitable for a particular application and only the right PCC can boost the quality of the end products. Precipitated calcium carbonate produced with a prismatic and rhombohedral-shape has maximum light dispersion at 0.4 to $0.5 \mu \mathrm{m}$ sized particles while a scalenohedral-shaped precipitated calcium carbonate has maximum light dispersion of 0.9 to $1.5 \mu \mathrm{m}$ particles. ${ }^{2}$ PCC of nanometer sized with rhombohedral morphology are highly effective for use as coating in a paper making. ${ }^{3}$

There are several approaches in the prior art to synthesize PCC having definite property like high purity, most of which are conversely focussing on this single property only. Although the processes do not allow full control of other properties such as crystal morphology, particle sizes, etc. ${ }^{4}$

The advantage of PCC lies in the prospect of tailor making the products with definite particle morphology, particle size and distribution as well as specific surface area (BET). PCC is a refined natural form of limestone using techniques. The purity can be increased to $99.9 \%$ or $99.999 \%$, and grain size can be controlled in a range from submicron to more than 10 micron. ${ }^{5}$ Calcium carbonate occurs in different crystalline polymorphs at

* To whom correspondence should be addressed. E-mail: kamarsha@ usm.my ambient pressure. There are anhydrous phases of aragonite, vaterite, calcite and hydrated phases of monohydrocalcite as well as hexahydrocalcite. ${ }^{6}$ The anhydrous $\mathrm{CaCO}_{3}$ can be classified as rhombic calcite, needle-like aragonite or spherical vaterite and among them calcite is known to be the most stable phase under ambient atmospheric conditions. ${ }^{7}$ The formation of any of these three polymorphs is strictly dependent on some parameters such as the temperature, supersaturation and $\mathrm{pH}$ of reaction solution. ${ }^{8}$ The control of calcium carbonate polymorphism is an intricate interplay amid thermodynamic and kinetic factors. ${ }^{9}$ The work by Ciullo ${ }^{10}$ shows that high purity PCC (>95\%) can be produced using pseudo-catalytic lixiviant to selectively extract calcium from slag material before being dissolved as PCC. Also Adams ${ }^{11}$ showed that high purity PCC can be produced from steel slag using ammonium salts to selectively extract calcium from slags. They reported that the smallest solid to liquid ratio of $5 \mathrm{~g} \mathrm{~L}^{-1}$ resulted in maximum calcium extraction efficiency $(73 \%)$ while using $100 \mathrm{~g} \mathrm{~L}^{-1}$ produced the lowest extraction efficiency of $6 \%$. Liu et al. ${ }^{12}$ tested the performance of two organic acid (succinic and acetic acid) for the possible extraction of calcium from steel slag for PCC production. They reported that the carbonation of succinic acid leachate did not result in the production of PCC, whereas, the carbonation of acetic acid leachate resulted in the synthesis of PCC.

A study by Suwanthai et al. ${ }^{13}$ shows that high purity PCC (mainly calcite) can be synthesized from gypsum waste by using an acid gas $\left(\mathrm{H}_{2} \mathrm{~S}\right)$ to improve the aqueous dissolution of the poorly soluble $\mathrm{CaS}^{14}$, produced high purity PCC (mainly amorphous) from medium and low grade limestone using strongly acidic cation exchange resin. This improvement was due to 
the reaction of $\mathrm{HCO}_{3}^{-}$in aqueous solution during the slaking reaction process. Valuable information from their work shows that they were able to eliminate the influence of impurities during the carbonation reaction. Furthermore, Chen et $a l^{15}$ studied a reaction precipitation of calcium carbonate by bubbling $\mathrm{CO}_{2}$ gas through a double-tube gas injection nozzle into milk of lime (MOL) solution in an agitated closed batch reactor. In their study, they observed that particle morphology and nucleation were closely related to the reaction $\mathrm{pH}$ of solution.

The recarbonation process is the most common technique of producing PCC. It is a complex process and involves simultaneous dissolution of $\mathrm{Ca}(\mathrm{OH})_{2}$ and $\mathrm{CO}_{2}$ as well as the crystallization of $\mathrm{CaCO}_{3}$. Carbonation is generally carried out in a series of reactors under closely controlled operating conditions to produce the required PCC morphology and particle size distribution (PSD). Luo et al. ${ }^{16}$ studied the synthesis of vaterite PCC via carbonation route under controlled $\mathrm{pH}$ condition. They reported that buffer solution highly influence the polymorphic phase of PCC while $\mathrm{CO}_{2}$ concentration and rate of gas flow have no significant influence. Furthermore, high purity spherical vaterite particles can be synthesized under controlled reaction conditions.

This work investigates the transition effects of reactant concentration and gas flow rate on PCC morphology and crystallite size using gas-liquid route via a modified batch-wise, bubblecolumn type reactor.

\section{Materials and Experimental Methodology}

In this research, limestone used for the experiments was calcined in a muffle furnace at an optimum disassociation temperature and resident time. The raw materials used in this research are high purity limestones, which are generally free from any major contaminants (purity $>98 \%$ ) for 'milk of lime' with less than $2 \%$ impurities made of mostly silica $\left(\mathrm{SiO}_{2}\right)$. However, the impurity does not present any significant discoloration in the final PCC.

Chunks of limestone were crushed into a manageable size range of 10-20 mm diameter before calcined in a muffle furnace at an optimum disassociation temperature and resident time. High reactive and low decrepitating quicklime $(\mathrm{CaO})$ was attained at an optimum calcining temperature of $1100{ }^{\circ} \mathrm{C}$ at $90 \mathrm{~min}$. The resulted quicklime is then hydrolyzed into distilled water to produce creamy hydrated-lime. In the slaking process, lumps of quicklime disintegrated to produce creamy white smooth paste of hydrated-lime $\mathrm{Ca}(\mathrm{OH})_{2}$ suspension, and is subsequently diluted in excess distilled water to produce different 'milk of lime' molarities. The resulting 'milk of lime' suspension is then screened to remove any coarse grits and impurities to less than $105 \mu \mathrm{m}$. Presence of trace amount of aluminium-silicate bearing minerals such as fine clay particles, carbonaceous matters, over burned or residual calcium carbonate generally has insignificant effect on the slaking process. The resulted PCC produced from various experimental designs were carried out to characterize its crystal morphology, particle size distribution pattern, state of agglomeration, and chemical purity. Table 1 shows the experimental designs for these experiments.

\subsection{Precipitation/Recarbonation Process}

These experiments were carried out in a one liter modified batch-wise, bubble-column type reactor (Fig. 1) containing $500 \mathrm{~mL}$ milk of lime with a constant stirring speed of $300 \mathrm{rpm}$ (the optimum stirring speed in this experiment). The experiment was designed to investigate and foresee the influence of reactant concentration and gas flow rate towards resulted PCC characteristics and precipitation process mechanisms. This is especially in
Table 1 Experimental designs for the experiments.

\begin{tabular}{lcc}
\hline $\begin{array}{l}\text { Experiment } \\
\text { No. }\end{array}$ & $\begin{array}{c}\text { Reactant concentration } \\
/ \mathrm{M}\end{array}$ & $\begin{array}{c}\text { Gas flow rate }-\mathrm{CO}_{2} \\
/ \mathrm{mL} \mathrm{min}-1\end{array}$ \\
\hline PCC A1 & 0.2 & 224.0 \\
PCC A2 & & 379.5 \\
PCC B1 & 0.56 & 224.0 \\
PCC B2 & & 379.5 \\
PCC C1 & 0.8 & 224.0 \\
PCC C2 & & 379.5 \\
PCC D1 & 1.0 & 224.0 \\
PCC D2 & & 379.5 \\
PCC D3 & 1.5 & \\
PCC E1 & & 224.0 \\
PCC E2 & & 379.5 \\
PCC F1 & 2.0 & 224.0 \\
PCC F2 & & 379.5 \\
PCC P8 & & \\
\hline
\end{tabular}

the terms of crystal morphology and growth sizes of PCC formed under specific operating conditions and parameters setting. In this case, precipitation or recarbonation processes were conducted at two predetermined $\mathrm{CO}_{2}$ gas flow rates over a period of 60 and 90 min resident time. Reactant concentrations were fixed between 0.2 and $2.2 \mathrm{M}$, and conducted at ambient temperature and pressure conditions, respectively.

The $\mathrm{pH}$, reaction temperature, conductivity/resistivity and total dissolved solid (TDS) of the reactant during the stages of recarbonation process were closely monitored (using Istek K4000-EC) for the product characteristics and process mechanism analysis. The resultant PCC after recarbonation were recovered by filtering through membrane filter, washed using distilled water and dried at $105^{\circ} \mathrm{C}$ for $24 \mathrm{~h}$ and subsequently analyzed for morphology, particle size distribution, and purity. Effects of the concentration and $\mathrm{CO}_{2}$ flow rates on particle morphology and size were investigated. The degree of recarbonation to form PCC was determined by loss on ignition (LOI). The morphology and particle size of PCC of each samples were examined under scanning electron microscope (SEM). Prior to SEM examination, these PCC powders were dispersed in methanol and ultrasonically treated to reduce particle aggregation.

\section{Results and Discussion}

In the carbonation process, solid $\mathrm{Ca}(\mathrm{OH})_{2}$ is first dissolved as soluble $\mathrm{Ca}^{2+}$ and $\mathrm{OH}^{-}$ions, while $\mathrm{CO}_{2}$ is absorbed in water in the form of weak $\mathrm{H}_{2} \mathrm{CO}_{3}$ and then converted to $\mathrm{H}^{+}, \mathrm{HCO}_{3}^{-}$and $\mathrm{CO}_{3}{ }^{2-}$ ions. Then $\mathrm{Ca}^{2+}$ combines with $\mathrm{CO}_{3}{ }^{2-}$ to form $\mathrm{CaCO}_{3}$, whilst $\mathrm{H}^{+}$ and $\mathrm{OH}^{-}$merge to form $\mathrm{H}_{2} \mathrm{O}$. The rate of recarbonation seems directly related to the reactant concentration, bubbling time and $\mathrm{CO}_{2}$ gas flow rate conditions, and eventually affects the characteristics of the resulting PCC.

$\mathrm{Ca}(\mathrm{OH})_{2}$ (aq.) $+\mathrm{CO}_{2}(\mathrm{~g}) \Rightarrow \mathrm{CaCO}_{3}+\mathrm{H}_{2} \mathrm{O}$

\subsection{Effects on Conductivity and $\mathrm{pH}$}

Reactant concentration at a particular time during the course of the reaction can be monitored by conductivity and $\mathrm{pH}$. During the course of precipitation, the $\mathrm{pH}$, conductivity (Fig. 2) and TDS values gradually decreases in tandem with the progress of recarbonation process and abruptly dropped to the lowest level at specific moments during the course of precipitation. At low initial concentrations, the solid $\mathrm{Ca}(\mathrm{OH})_{2}$ is rapidly dissolved and depleted in a short period of time during the course 


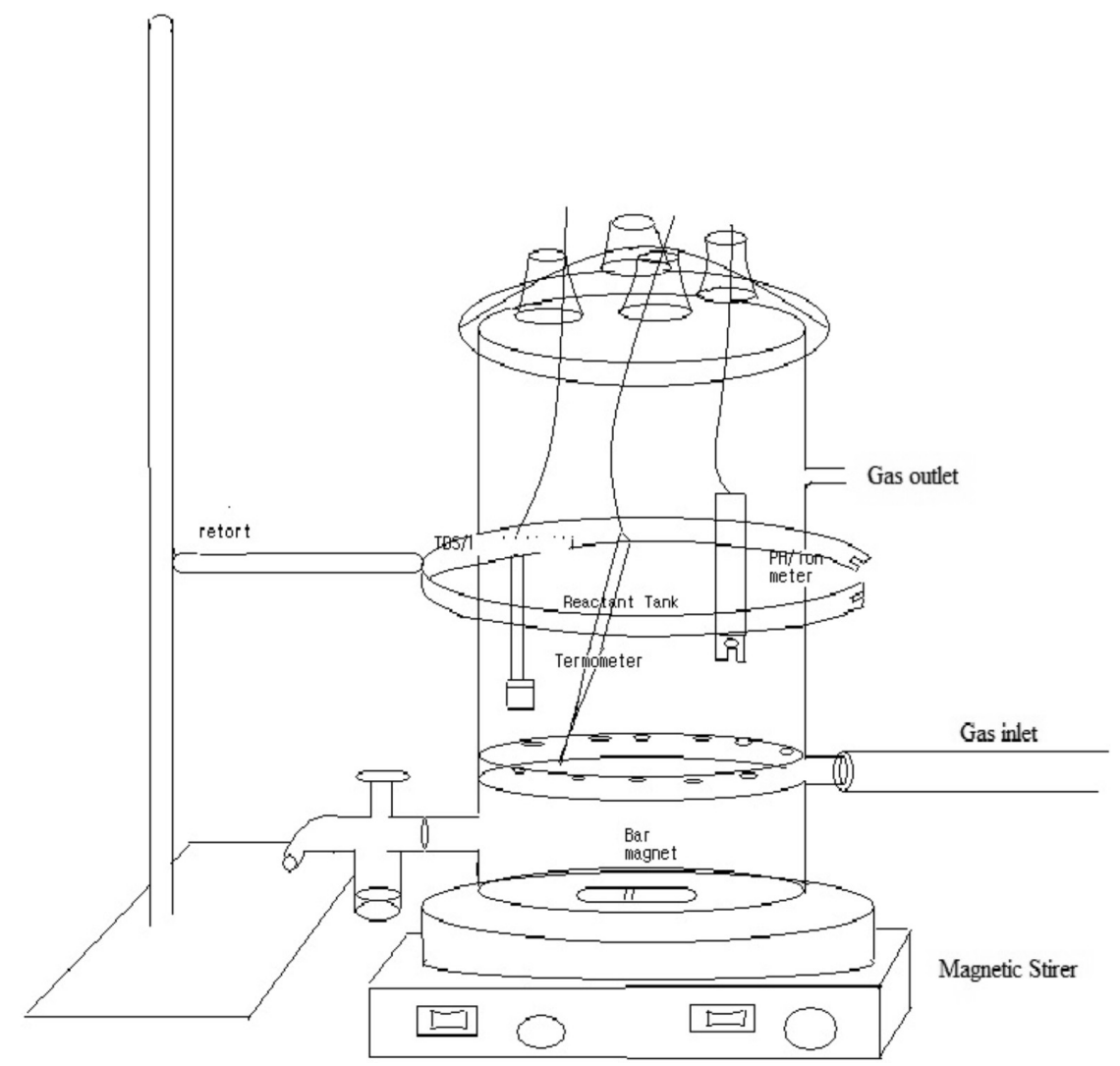

Figure 1 Modified batch-wise, bubble-column type reactor.

of precipitation to form PCC crystallite. Rapid consumption of $\mathrm{Ca}^{2+}$ and $\mathrm{OH}^{-}$witnessed a decrease in $\mathrm{pH}$ of 12 to neutral ( $\left.\mathrm{pH} 7\right)$, TDS and conductivity values.

This consequently will affect the characteristics of produced PCC, e.g. particulate sizes and crystal morphology. Dissolution of $\mathrm{Ca}(\mathrm{OH})_{2}$ and $\mathrm{CO}_{2}$ increases the concentration of ionic charges dissolved species, i.e. $\mathrm{Ca}^{2+}, \mathrm{OH}^{-}, \mathrm{HCO}_{3}^{-}, \mathrm{CO}_{3}^{2-}, \mathrm{CaOH}^{+}$and $\mathrm{CaHCO}_{3}{ }^{+}$during recarbonation. Progress in recarbonation, gradually generated $\mathrm{CaCO}_{3}$ in the form of solids particles (less dissolved species), hence reduces the electrokinetic ability as well as resulted to decrease in conductivity ability. This indicates

(a)

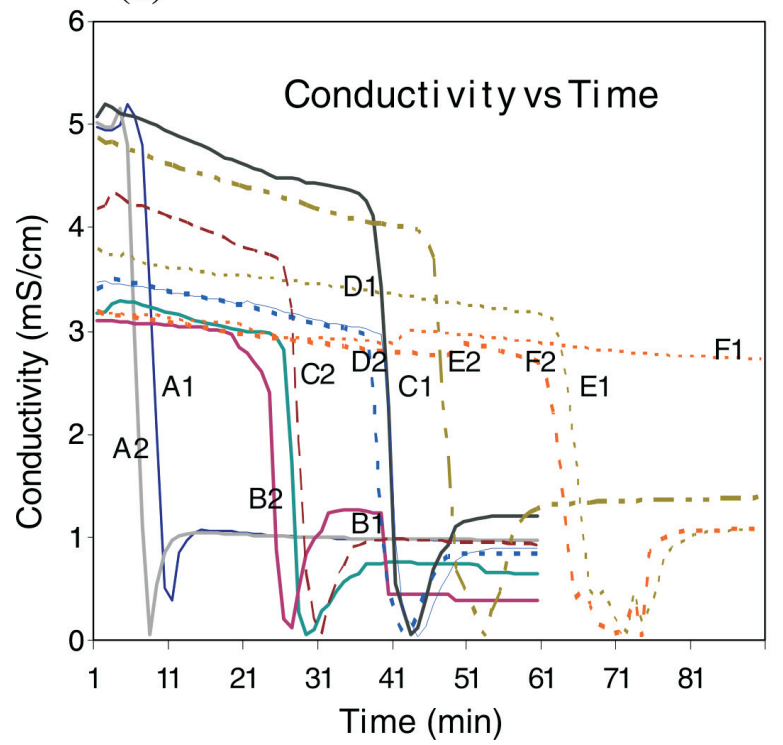

that a complete PCC precipitation process was attained at a point where there were no more excess $\mathrm{Ca}^{2+}$ available. Higher reactant concentrations need a longer bubbling time, and this can be compensated by increasing the gas flow rate. Excess gas supply only resulted in dissolved $\mathrm{CO}_{2}$ to form a weak $\mathrm{HCO}_{3}^{-}$, and normally show a slight rebound in conductivity values (Fig. 2).

\subsection{Effect on Resistivity, Total Dissolved Solid (TDS) and Temperature}

Figure 3 shows a sudden and brief peak-up in resistivity

(b)

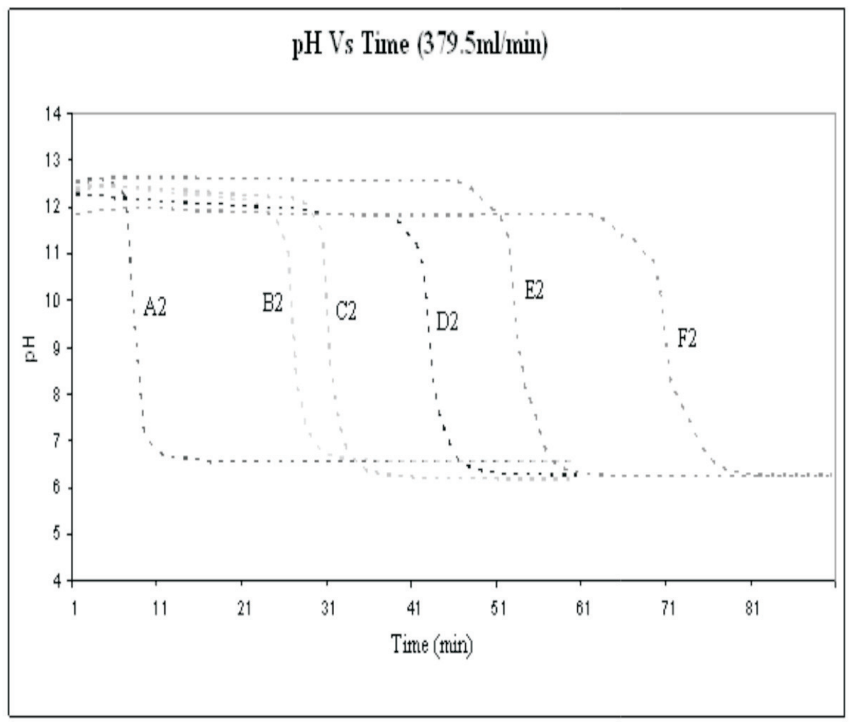

Figure 2 The changes in trend of (a) conductivity labelled A-F and (b) pH labelled A-F during the course of PCC precipitation process. 
(a)

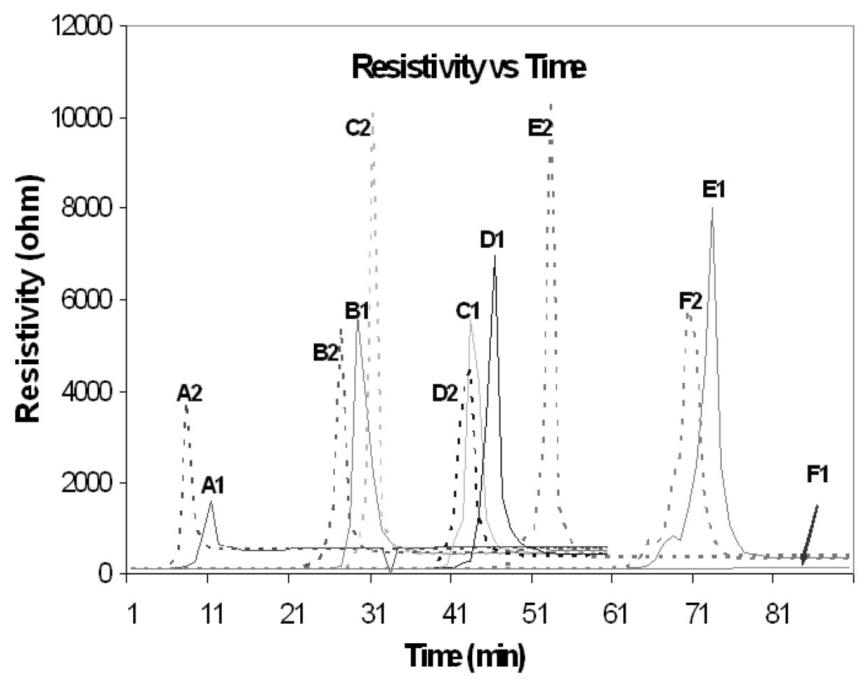

(b)

Temperature Vs Time $(379.5 \mathrm{ml} / \mathrm{min})$

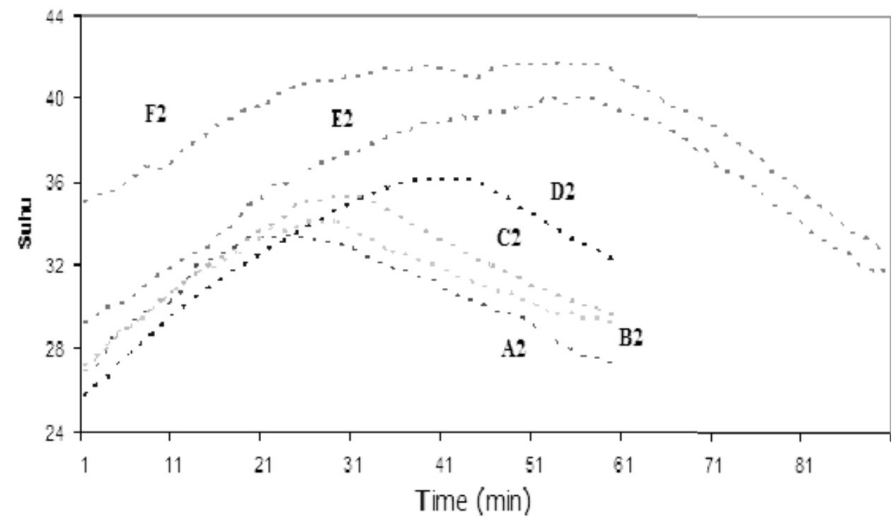

Figure 3 (a) Sudden and briefly peak-up in resistivity values and (b) exothermic heat released during the recarbonation process at $379.5 \mathrm{~mL} \mathrm{~min}{ }^{-1} \mathrm{gas}$

values, which occurred at the same 'dropped points' as in $\mathrm{pH}$ and conductivity trends. TDS values were also exhibiting similar trend as in conductivity and $\mathrm{pH}$.

The TDS (mg L-1) usually drop to zero simultaneously with $\mathrm{pH}$ and conductivity at the same moments. Higher reactant concentration of $2.0 \mathrm{M}$ and $1.5 \mathrm{M}$ (PCC-E2 and PCC-F2) requires longer recarbonation time. This can also be shortened by increasing the gas flow rate. However, morphology and other crystal characteristic of resulted PCC would not be the same. PCC precipitation is an exothermic chemical reaction. In this study, the rise in temperature during the course of precipitation were observed in the order of 10 to $15^{\circ} \mathrm{C}$ (Fig. 3). Higher reactant concentrations (e.g. 2.M in PCC F2) yielded greater amount of heat as compared to the lower one.

\subsubsection{XRD and FTIR Analysis}

Figure 4 shows the gradual changes in the XRD patterns of PCC produced at various operating variables and conditions.

Gradual increase in intensity was in tandem with phase concentration or growth rate of PCC followed by the reduction of $\mathrm{Ca}(\mathrm{OH})_{2}$. Irrespective of reactant temperature, the growth rate

(a)

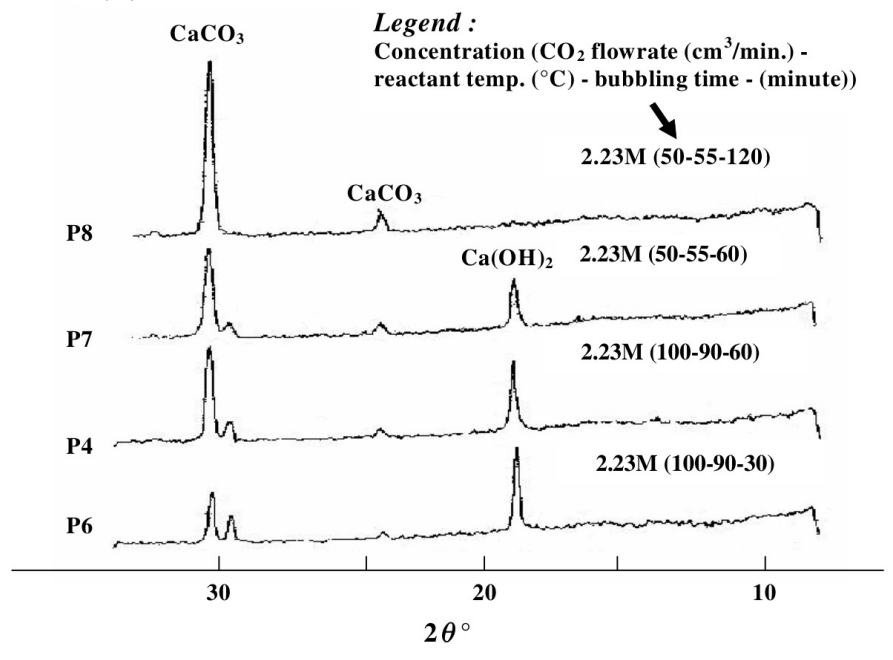

of PCC increased with longer bubbling times. It seems that operating temperature around $50{ }^{\circ} \mathrm{C}$ favoured crystallization of rhombohedra calcite PCC. XRD pattern for experimental design as shown in Table 1 is almost identical and consistent because of the complete formation to calcite phase in all experimented samples. All the samples show almost similar peak position and intensity. No peaks of $\mathrm{Ca}(\mathrm{OH})_{2}$ was present, thus indicating a complete recarbonation. Marked different in crystal morphology characteristics as shown by SEM micrographs (Fig. 5) can only be revealed by Fourier transform infrared spectroscopy (FTIR). FTIR spectrum shows typical absorption peaks of calcite around 1433, 874 and $713 \mathrm{~cm}^{-1}$ (Fig. 4). This indicates that the formed PCC have, somewhat, variation in crystal morphology or atomic structure during precipitation, which is hard to be defined by the XRD spectrum.

\subsubsection{Chemical Composition and Purity}

Tables 2 and 3 presents the results of XRF and LOI analysis. LOI is best used to determine $\mathrm{CaCO}_{3}$ content. The mass loss corresponds to the released amount of $\mathrm{CO}_{2}(44 \mathrm{wt} . \%)$ during the firing process above dissociation temperature of limestone. (b)

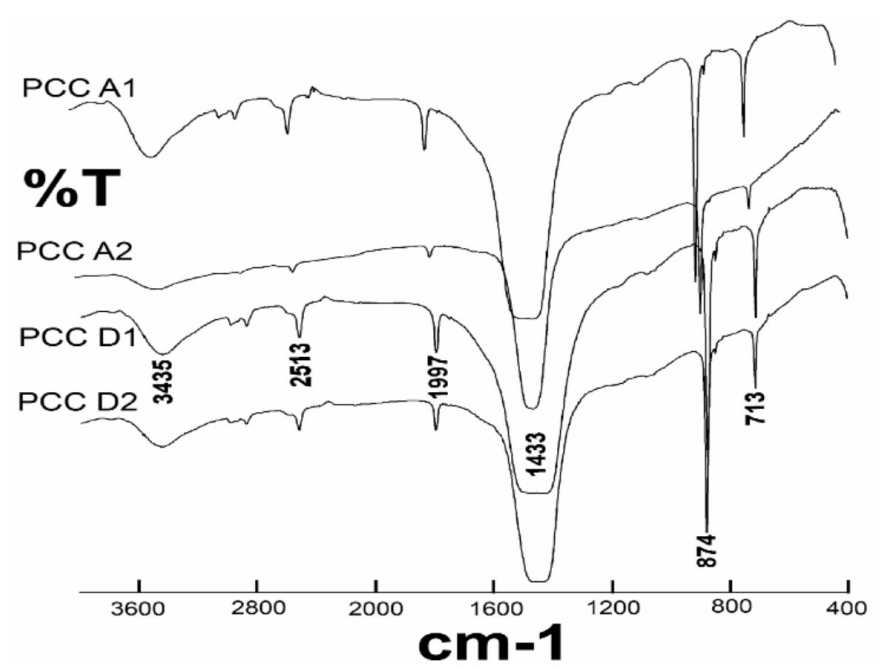

Figure 4 (a) XRD and (b) FTIR spectra of selected synthesized PCC produced at different operating variables and conditions. 


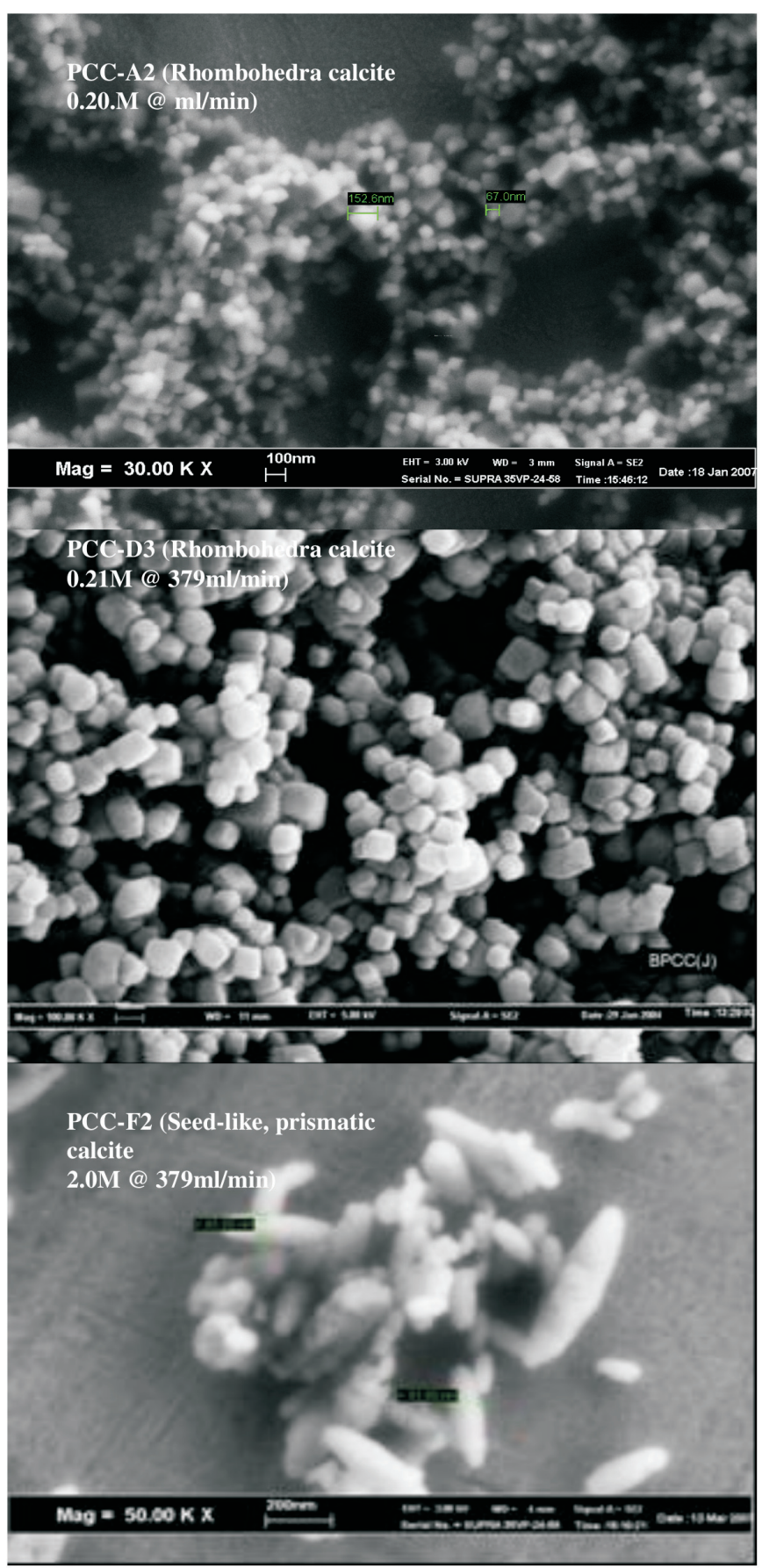

Figure 5 Crystal morphology and particles size distribution of lower (A2, D3) concentration and higher concentration (D2, B2, F2) PCC from this experiments and also PCC-P8 after Ariffin. ${ }^{21}$

Results indicated that the produced PCC is very high in purity with an average of about $98.6 \%$. Other components, which are normally inherited from precursor stone are often less than $1.5 \%$.

\subsubsection{Crystal Morphology}

Figure 4 shows examples of the crystal phases of PCC produced at the selected concentrations, gas flow rates and bubbling times. Generally, calcium carbonate mineral phases crystallized into three common crystal polymorphs (calcite, aragonite and vaterite). However, there are other crystal morphologies that have been discovered depending on different kind of operating techniques and reactant used. At ambient conditions, calcite is a thermodynamically stable form of carbonate and has cubical
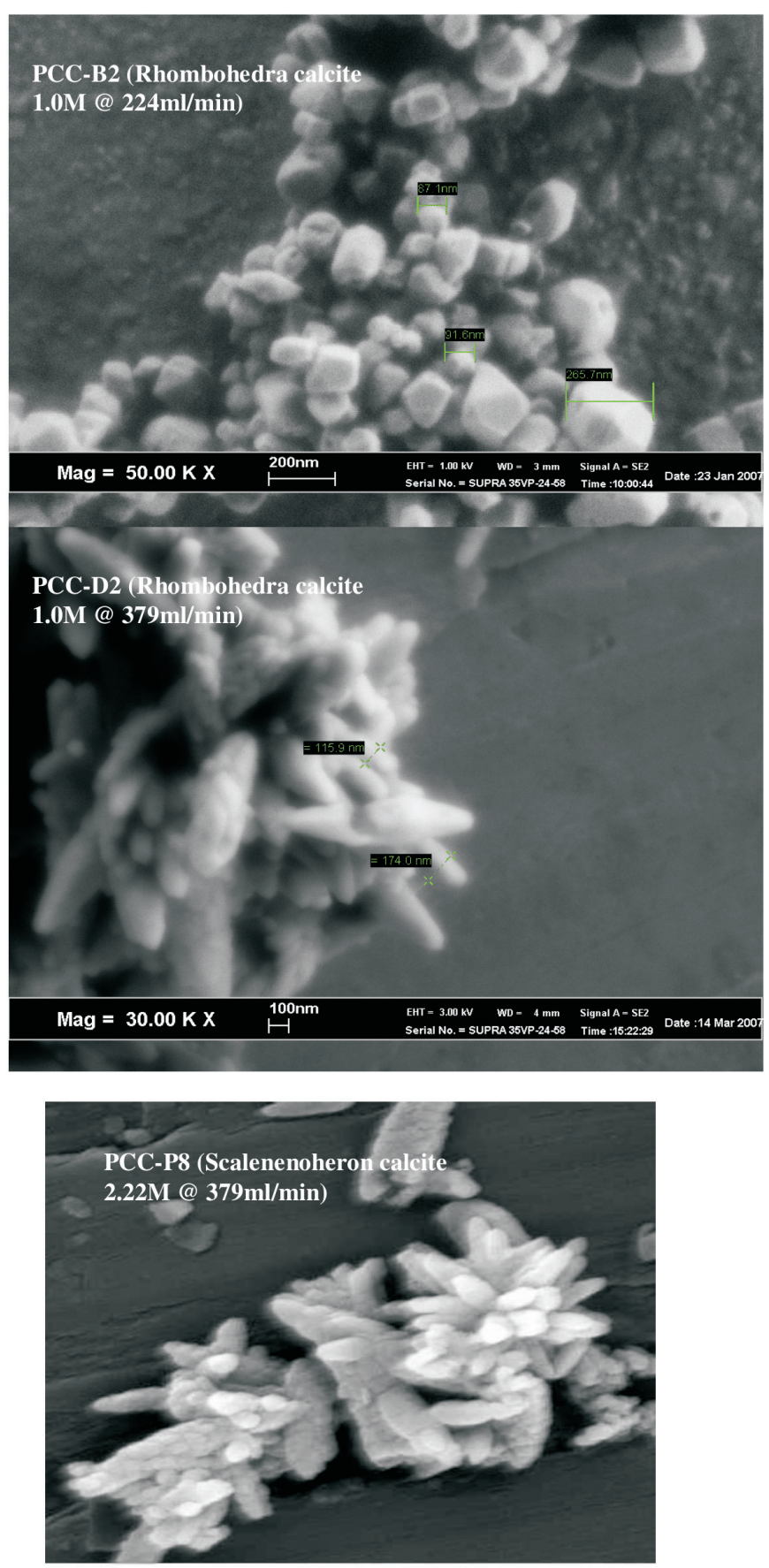

00103 25kU 0.5U rhombohedra crystal morphology. At a lower reactant concentration (e.g. PCC-A1-0.2 M), well-developed cubic-like, rhombohedra calcite were generally formed within the size order of 50 to $100 \mathrm{~nm}$ (Fig. 5). This result obtained by using the modified reactor can be compared with results by several authors using chemical additives to achieve smaller PCC particle sizes. Konopacka-Łyskawa et al. ${ }^{17}$ synthesized PCC particles using aqueous of isopropyl alcohol, n-butanol and glycerol as solvent on lime slurry using carbonation process. They reported that an increment of reactive mixture of isopropyl alcohol and n-butanol concentration resulted in the high yield of smaller PCC particles of approximately $2.5 \mu \mathrm{m}$. However, finer PCC particles size of $0.1-0.59 \mu \mathrm{m}$ were formed when single solution of $20 \%$ glycerol concentration was used. Feng and Yon ${ }^{18}$ reported 
Table 2 XRF Analysis of PCC.

\begin{tabular}{lll}
\hline \multirow{2}{*}{ Component } & \multicolumn{2}{c}{$/$ wt. \% } \\
\cline { 2 - 3 } & PCC 2 & PCC D1 \\
\hline $\mathrm{Al}_{2} \mathrm{O}_{3}$ & 0.17 & 0.15 \\
$\mathrm{SiO}_{2}$ & 0.24 & 0.19 \\
$\mathrm{~K}_{2} \mathrm{O}$ & 0.015 & Trace \\
$\mathrm{CaCO}_{3}$ & 99.0 & 98.0 \\
$\mathrm{Fe}_{2} \mathrm{O}_{3}$ & 0.034 & 0.014 \\
$\mathrm{NaO}$ & 0.019 & 0.02 \\
$\mathrm{CuO}$ & 0.10 & 0.10 \\
$\mathrm{SrO}$ & - & 0.02 \\
$\mathrm{P}_{2} \mathrm{O}_{3}$ & - & 0.03 \\
$\mathrm{MgCO}_{3}$ & - & 1.1 \\
\hline
\end{tabular}

Table 3 LOI (\%) of synthesized PCC.

\begin{tabular}{lcccc}
\hline $\begin{array}{l}\text { Expt. } \\
\text {-sample no }\end{array}$ & $\begin{array}{c}\text { Before fired } \\
/ \mathrm{g}\end{array}$ & $\begin{array}{c}\text { After fired } \\
/ \mathrm{g}\end{array}$ & $\begin{array}{c}\text { LOI } \\
/ \%\end{array}$ & $\begin{array}{c}\mathrm{CaCO}_{3} \\
/ \%\end{array}$ \\
\hline PCC A1 & 1.0017 & 0.5672 & 43.38 & 98.60 \\
PCC A2 & 1.0003 & 0.5673 & 43.29 & 98.38 \\
PCC B1 & 1.0060 & 0.5641 & 43.93 & 99.84 \\
PCC B2 & 1.0015 & 0.5598 & 44.10 & 100.0 \\
PCC C1 & 1.0020 & 0.5601 & 44.10 & 100.0 \\
PCC D1 & 1.0009 & 0.5620 & 43.85 & 99.66 \\
PCC D2 & 1.0002 & 0.5592 & 44.09 & 100.0 \\
PCC E1 & 1.0054 & 0.5627 & 44.03 & 100.0 \\
PCC E2 & 1.0029 & 0.5685 & 43.31 & 98.43 \\
PCC F2 & 1.0008 & 0.5701 & 43.04 & 97.81 \\
\hline
\end{tabular}

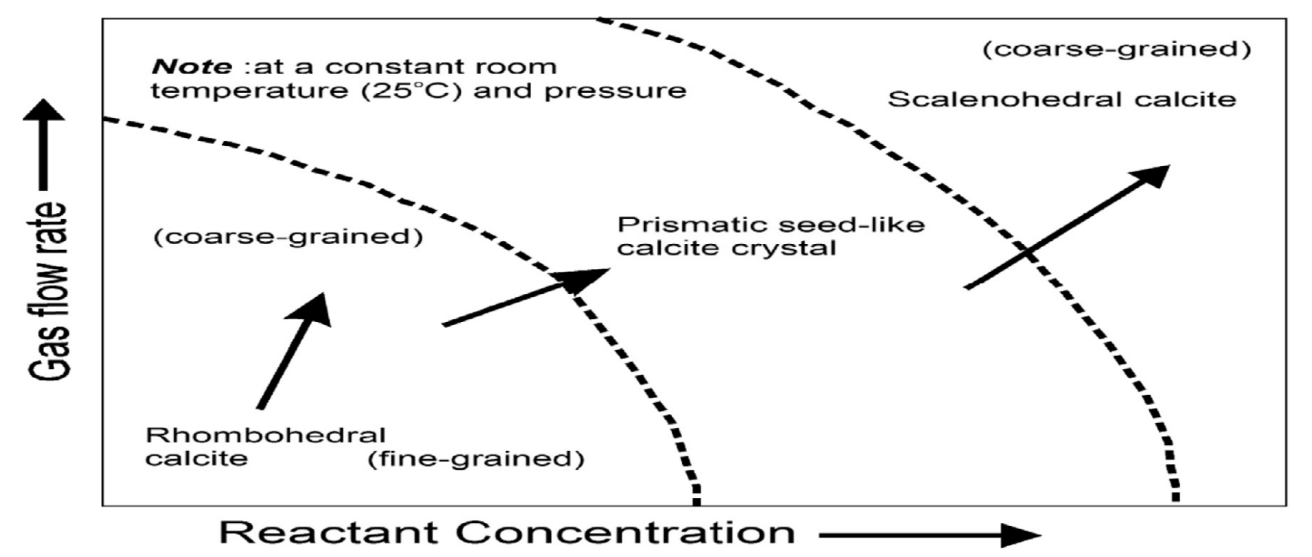

Figure 6 Crystallization hypothesis for PCC production in the liquid-gas system from $\mathrm{Ca}(\mathrm{OH})_{2}$ suspension.

an average particle size of 1 to $3 \mu \mathrm{m}$ at ambient temperature when EDTA and terpineol were used. Studies by Xiang et al. ${ }^{19}$ also reported that addition of $1 \%(\mathrm{w} / \mathrm{w}) \mathrm{ZnCl}_{2}$ shows an obvious decrease in PCC particle size and $0.2 \mu \mathrm{m}$ diameter of spherical PCC particles was formed.

Further increase of flow rate $\left(379 \mathrm{~mL} \mathrm{~min}^{-1}\right)$ resulted in slightly coarser PCC (PCC-A2). This is consistent with the work by Agnihotri et al. ${ }^{20}$, that the particle size decreases with decrease in $\mathrm{CO}_{2}$ concentration. Reactant concentration (PCC-B1-0.5M) often doubled the crystal size of these rhombohedra PCC within the order of 100 to $150 \mathrm{~nm}$. Higher gas flow rate at $379 \mathrm{~mL} \mathrm{~min}^{-1}$ does not result to much change in size of this PCC-B2. At the $224 \mathrm{~mL} \mathrm{~min}^{-1}$ gas flow rate, the resultant PCC-D1 retained its initial rhombohedron shape. Gradual transformation of calcite rhombohedra to prismatic (seed-like) calcite morphology was only observed at the $1.0 \mathrm{M}$ with $379.5 \mathrm{~mL} \mathrm{~min}^{-1}$ (PCC-D2) gas flow rate. This PCC-D2 possesses a crystal dimension of $175 \mathrm{~nm}$ by $100 \mathrm{~nm}$. At the higher concentration of $2.22 \mathrm{M}$ (PCC-P8), scalenohedron calcite PCC was precipitated. 'Milk of lime' concentrations higher than $1.0 \mathrm{M}$, usually exhibit prismatic 'seed-like' PCC morphology (PCC-F1 and PCC-F2). They usually possess larger particle sizes than $400 \mathrm{~nm}$ by $120 \mathrm{~nm}$. The PCC crystallization or formation in relation to the liquid-gas reaction such as in this study could be demonstrated by the reaction diagram (Fig. 6).

A study by Ariffin ${ }^{21}$ showed that concentration higher than 2.0 M with prolonged bubbling time would only result in rosette-like scalenohedron PCC formation.

\section{Conclusions}

'Milk of lime' concentration, gas flow rate and residence time are the main operating parameters and variables in PCC produc- tion control. By varying such variables and conditions, we were able to understand and manipulate crystal morphology and other characteristics like crystallite size and distribution patterns by using limestone as a starting commercial material. A low reactant concentration $(0.2 \mathrm{M})$ favours the formation of cubic-like, rhombohedra calcite with almost uniform particle size distribution. Increasing the reactant concentration to specific levels, e.g. up to $0.56 \mathrm{M}$, prismatic calcite morphology start to emerge. At higher level 'milk of lime' concentration such as at $2.0 \mathrm{M}$ and $2.2 \mathrm{M}$, scalenohedron calcite was gradually formed. The crystallization hypothesis would be useful in predicting the production of desired PCC characteristics rather than varying those operating variables. This model diagram can easily be modified to include effects of reactant temperature, pressure and presence of additives later.

\section{Acknowledgement}

The second author acknowledges Universiti Sains Malaysia (USM) for an e-science fund fellowship grant.

\section{References}

1 J.A. Onimisi, R. Ismail, K.S. Ariffin, N. Baharun and H.B. Hussin, A novel rapid mist spray technique for synthesis of single phase precipitated calcium carbonate using solid-liquid-gas process, Korean J. Chem. Eng., 2016, 1-5.

2 S.-T. Liu and M. R. Hart, Google Patents, 2008.

3 (a) G.J. Price, M.F. Mahon, J. Shannon and C. Cooper, Composition of calcium carbonate polymorphs precipitated using ultrasound, Cryst. Growth Des., 2010, 11, 39-44; (b) W. A. Khanday, S. A. Majid, S. C. Shekar and R. Tomar, Synthesis and characterization of various zeolites and study of dynamic adsorption of dimethyl methyl phosphate over them, Mater. Res. Bull., 2013, 48, 4679-4686.

4 M. Stroescu, A. Stoica-Guzun, S.I. Jinga, T. Dobre, I.M. Jipa and L.M. Dobre, Influence of sodium dodecyl sulfate and cetyl trimethyl- 
ammonium bromide upon calcium carbonate precipitation on bacterial cellulose, Korean J. Chem. Eng., 2012, 29, 1216-1223.

5 T. Oates, Lime and Limestone, Wiley Online Library, 2007.

6 L.S. Gomez-Villalba, P. López-Arce, M. Alvarez de Buergo and R. Fort, Atomic defects and their relationship to aragonite-calcite transformation in Portlandite nanocrystal carbonation, Cryst. Growth Des., 2012, 12, 4844-4852.

7 S. Knez, D. Klinar and J. Golob, Stabilization of PCC dispersions prepared directly in the mother-liquid after synthesis through the carbonation of (hydrated) lime, Chem. Eng. Sci., 2006, 61, $5867-5880$.

8 (a) G. Montes-Hernandez, D. Daval, R. Chiriac and F. Renard Growth of nanosized calcite through gas-solid carbonation of nanosized Portlandite under anisobaric conditions, Cryst. Growth $\mathcal{E}$ Des., 2010, 10, 4823-4830; (b) A.R. Ibrahim, J.B. Vuningoma, Y. Huang, $\mathrm{H}$. Wang and J. Li, Rapid carbonation for calcite from a solid-liquidgas system with an imidazolium-based ionic liquid, Int. J. Mol. Sci., 2014, 15, 11350-11363.

9 S. Shirsath, S. Sonawane, D. Saini and A. Pandit, Continuous precipitation of calcium carbonate using sonochemical reactor, Ultrason. Sonochem., 2015, 24, 132-139.

10 P.A. Ciullo, Industrial Minerals and Their Uses: a Handbook and Formulary, William Andrew, Westwood, New Jersey, U.S.A., 1996.

11 R.D. Adams, Adhesive Bonding: Science, Technology and Applications, Elsevier, Abington, Cambridge, England, 2005.

12 Y.-Q. Liu, G.-H. Lan and P. Zeng, Size-dependent calcium carbonate precipitation induced microbiologically in aerobic granules, Chem. Eng. J., 2016, 285, 341-348.

13 W. Suwanthai, V. Punsuvon and P. Vaithanomsat, Optimization of biodiesel production from a calcium methoxide catalyst using a statistical model, Korean J. Chem. Eng., 2015, 33, 90-98.

14 S.-C. Huang, K. Naka and Y. Chujo, A carbonate controlled-addition method for amorphous calcium carbonate spheres stabilized by poly (acrylic acid)s, Langmuir, 2007, 23, 12086-12095.

15 P.-C. Chen, C. Y. Tai and K. Lee, Morphology and growth rate of calcium carbonate crystals in a gas-liquid-solid reactive crystallizer, Chem. Eng. Sci., 1997, 52, 4171-4177.

16 F. Luo, Z. Chen, M. Megharaj and R. Naidu, Simultaneous removal of trichloroethylene and hexavalent chromium by green synthesized agarose-Fe nanoparticles hydrogel, Chem. Eng. J., 2016, 294, 290-297.

17 D. Konopacka-Łyskawa, B. Kościelska and J. Karczewski, Effect of some organic solvent-water mixtures composition on precipitated calcium carbonate in carbonation process, J. Cryst. Growth, 2015, 418, 25-31.

18 B. Feng, A.K. Yong and H. An, Effect of various factors on the particle size of calcium carbonate formed in a precipitation process, Mater. Sci. Eng., A, 2007, 445-446, 170-179.

19 L. Xiang, Y. Xiang, Z. G. Wang and Y. Jin, Influence of chemical additives on the formation of super-fine calcium carbonate, Powder Technol., 2002, 129-133.

20 (a) R. Agnihotri, S. K. Mahuli, S.S. Chauk and L.-S. Fan, Influence of surface modifiers on the structure of precipitated calcium carbonate, Indust. Eng. Chem. Res., 1999, 38, 2283-2291; (b) B. Feng, A.K. Yong and $H$. An, Effect of various factors on the particle size of calcium carbonate formed in a precipitation process, Mater. Sci. Eng.: A, 2007, 445, 170-179.

21 K.S. Ariffin, Evaluation and Utilization of Malaysian Marble, PhD thesis University of Leeds, 2000, 268 